Simulating Small-Scale

Experiments of In-Tunnel Airblast

Using STUN and ALE3D

S. Neuscamman, L. Glenn, G. Schebler, L.

McMichael, L. Glascoe

September 12, 2011 
This document was prepared as an account of work sponsored by an agency of the United States government. Neither the United States government nor Lawrence Livermore National Security, LLC, nor any of their employees makes any warranty, expressed or implied, or assumes any legal liability or responsibility for the accuracy, completeness, or usefulness of any information, apparatus, product, or process disclosed, or represents that its use would not infringe privately owned rights. Reference herein to any specific commercial product, process, or service by trade name, trademark, manufacturer, or otherwise does not necessarily constitute or imply its endorsement, recommendation, or favoring by the United States government or Lawrence Livermore National Security, LLC. The views and opinions of authors expressed herein do not necessarily state or reflect those of the United States government or Lawrence Livermore National Security, LLC, and shall not be used for advertising or product endorsement purposes.

This work performed under the auspices of the U.S. Department of Energy by Lawrence Livermore National Laboratory under Contract DE-AC52-07NA27344. 


\section{Simulating Small-Scale Experiments of In-Tunnel Airblast Using STUN and ALE3D}

Stephanie Neuscamman, Lewis Glenn, Gregory Schebler, Larry McMichael, and Lee Glascoe

Lawrence Livermore National Laboratory 


\section{$\underline{\text { Introduction }}$}

This report details continuing validation efforts for the Sphere and Tunnel (STUN) and ALE3D codes. STUN has been validated previously for blast propagation through tunnels using several sets of experimental data with varying charge sizes and tunnel configurations, including the MARVEL nuclear driven shock tube experiment (Glenn, 2001). The DHS-funded STUNTool version is compared to experimental data and the LLNL ALE3D hydrocode. In this particular study, we compare the performance of the STUN and ALE3D codes in modeling an in-tunnel airblast to experimental results obtained by Lunderman and Ohrt in a series of small-scale high explosive experiments (1997).

In this study, we compare the performance of the STUN and ALE3D codes in modeling an in-tunnel airblast to experimental results. Blast pressure data were obtained by Lunderman and Ohrt in a series of small-scale high explosive experiments (Lunderman and Ohrt, 1997). In the experiment, a straight tunnel section was simulated with a $243 \mathrm{~mm}$ inner diameter steel pipe (10 in. Schedule 80 steel pipe). Pipe sections were connected with heavy bolted flanges to form an assembled tunnel about $7.75 \mathrm{~m}$ in length. The tunnel inlet was constructed with steel plates to emulate the entrance to a real tunnel in a mountainside. The far end of the pipe was generally left open. The pressure profiles were obtained using diaphragm-type airblast gages flush-mounted to the wall of the pipe. Spherical explosive charges were formed from hand-packed hemispheres of composition C-4. The hemispheres were packed around a detonator to approximate a center-detonated charge. The charge was suspended by the firing line of the detonator to the centerline of the pipe. A series of detonations were conducted, with the axial position of the charge varying from four diameters (4D) outside the tunnel inlet to 4D inside the tunnel (also measured from the tunnel portal). The experiments used $15.7 \mathrm{~g}, 31.4 \mathrm{~g}$ and $62.4 \mathrm{~g}$ of explosive in order to investigate scaling effects. The STUN and ALE3D calculations focused on the $15.7 \mathrm{~g}$ case with the charge located inside the pipe, 4D from the inlet; see Figure 1.

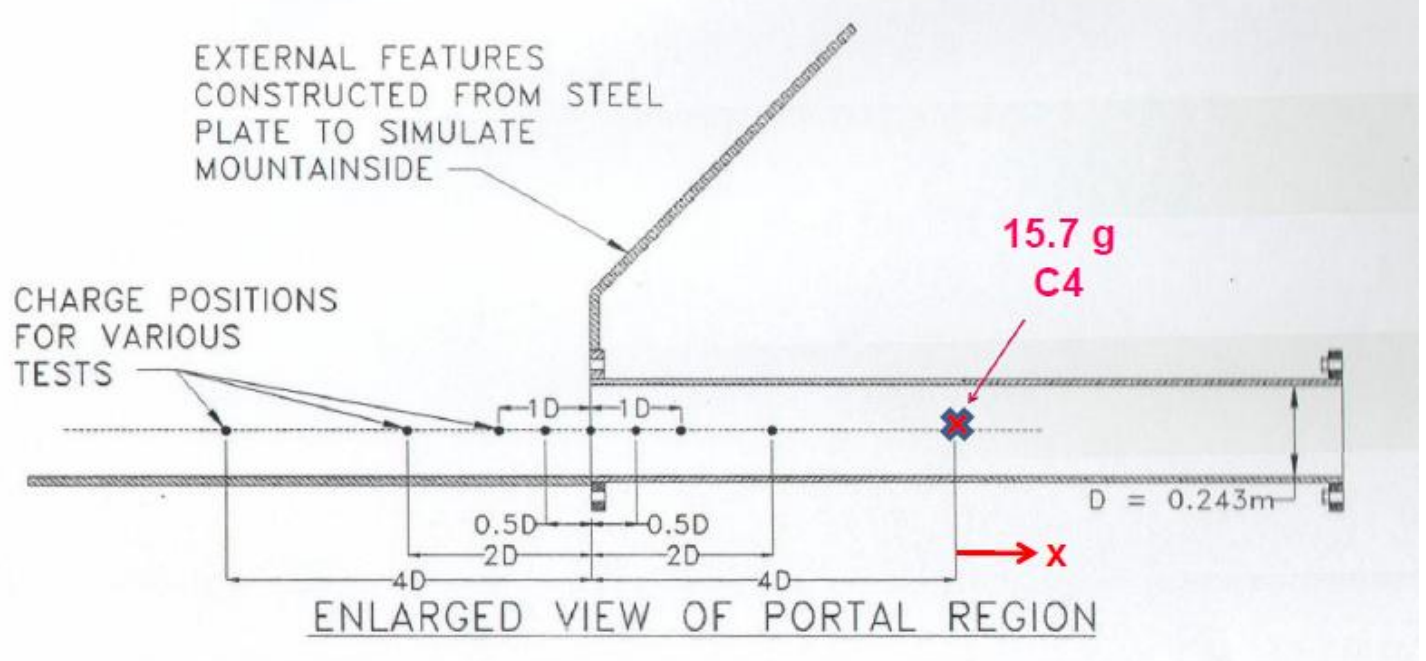

Figure 1: Experimental Configuration Schematic

\section{Simulation details: STUN}

The STUN (Sphere and TUNnel) code is a " $13 / 4-\mathrm{D}$ " code that uses a simplified algorithm to capture the essential physics occurring in blast propagation through a tunnel (Glenn, 2001). STUN is an Arbitrary Lagrangian Eulerian (ALE) code that couples a 1D spherical flow region around the detonation of the 
explosive to $1 \mathrm{D}$ axial flow in the tunnel. STUN is, in part, based on the one-dimensional wall drag model:

$$
\frac{d u}{d t}+\frac{1}{\rho} \frac{\partial p}{\partial x}+\frac{f}{4 r} u|u|=0
$$

where $u$ is the particle velocity in the $x$ direction, $\rho$ is the air density, $p$ is pressure in the tunnel, $A$ is the cross-sectional area of a tunnel of radius $r$, and the friction coefficient, $F=f / 4 r$. The friction factor, $f$, the Prandtl-Karman "Law of the Wall", is a function of the Reynolds number. The dimensions of the tunnel and the charge properties were matched to the experimental set up. The Jones-Wilkins-Lee (JWL) equation of state was used to model the energy released in detonation. There were 252 elements in the charge, and the downstream element size was $8.94 \mathrm{~mm}$. The simulation ran in less than a minute on a desktop PC (single processor).

\section{Simulation details: ALE3D}

ALE3D is a three-dimensional multi-physics computer code that utilizes Arbitrary Lagrangian Eulerian (ALE) techniques (Nicols, 2009). In this study, the flow was solved as a 2D axisymmetric system. Tunnel and charge geometry were matched to the experimental values. The steel pipe was not modeled; the boundary at the inner diameter of the pipe was assumed to be rigid. The JWL equation of state was used to model the energy released in detonation; air was modeled as an ideal gas. Two configurations were considered: in the first, half symmetry was assumed (the upstream tunnel was assumed to be identical to the downstream configuration for computational simplicity), and in the second, the full tunnel geometry was modeled. Mesh refinement effects were also investigated and found to be negligible at the resolutions considered, between $2.5 \mathrm{~mm}$ and $1.7 \mathrm{~mm}$. To obtain the results presented below, the grid for the symmetric tunnel had 48 radial elements in the spherical charge and a downstream air element size of $2.5 \mathrm{~mm}$ (Figure 2). The symmetric tunnel run completed in 3.6 hours on 8 processors. The full tunnel had 80 radial elements in the spherical charge and a downstream element size of $1.7 \mathrm{~mm}$. The full tunnel run completed in approximately 96 hours on 24 processors.

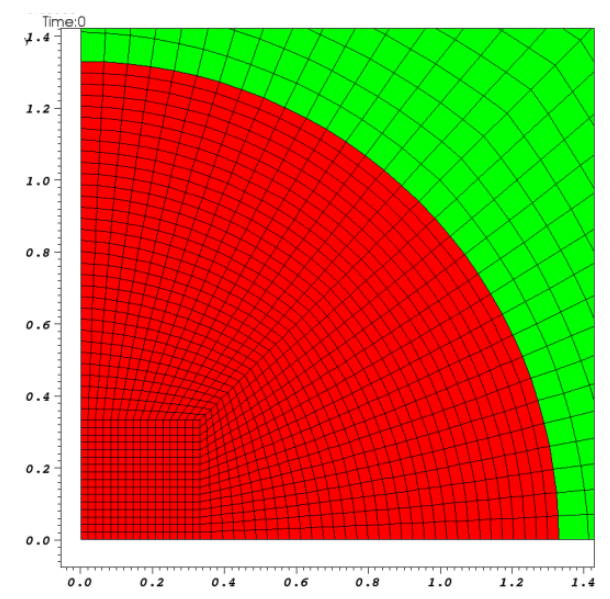

Figure 2: ALE3D grid with spherical charge (red) in air (green)

\section{$\underline{\text { Results }}$}

Figures 3-6 show the pressure profiles versus time for four measurement locations down-tunnel from the charge. Both simulations fail to capture peak pressure for the first measurement station, $x=0.74 \mathrm{D}$. 
However, based on the virtually instantaneous pressure rise and subsequent oscillation into the negative phase observed in the experimental profile, the authors suspect that the sensor bandwidth was insufficient to resolve the signal reported at this position and the reported peak pressure was erroneous. STUN pressure profiles at subsequent measurement positions are virtually congruent with the experimental ones. ALE3D pressure profiles from the symmetric tunnel show good agreement in arrival time and peak pressure further down the tunnel. However, due to the symmetry assumption, the symmetric tunnel simulation fails to capture the pressure relaxation into the negative phase at later times. The full tunnel simulation is able to capture the pressure relief and decay into negative phase very well.

Peak pressure results from each simulation and the experiment are shown in Figure 7. Both simulations show good agreement with the experimental data. The STUN calculation performs better than ALE3D for this metric, and agreement to experiment increases for peak pressure at $\mathrm{x} / \mathrm{D}$ locations greater than one. ALE3D peak pressure results shown are for the symmetric tunnel case; the results from the full tunnel simulation were indistinguishable. ALE3D agreement with the experiment also improves as distance from the explosive charge increases.

Peak impulse results from all three simulations and the experiment are shown in Figure 8. The STUN results again show good agreement with the experiment, with agreement improving further down the tunnel. The symmetric ALE3D results slightly over-predict peak impulse; the full tunnel ALE3D results under-predict the peak impulse. Since the symmetric ALE3D case does not correctly model the relaxation to negative pressure, we expect some amount of over-prediction in the impulse results. Furthermore, since the peak pressures are somewhat under-predicted by ALE3D, we expected that the peak impulse would also be under-predicted when the full tunnel simulation was run to correct the pressure relaxation.

\section{Conclusions}

Two different hydrodynamic codes, STUN and ALE3D, were used to simulate a small-scale highexplosive blast in a tunnel and the results were compared to experimental data. In general, both codes reproduced the experimental data quite well, however at the data position closest to the charge there were discrepancies and these appeared to be linked to insufficient bandwidth in the experimental apparatus. Simulating the full tunnel in ALE3D resulted in better agreement with the experiment in the pressure profiles at late times, but reduced the peak impulse.

For the experimental set up of a high explosive blast propagating in a straight, smooth pipe, both STUN and ALE3D achieved good agreement with experimental results and each other. This exercise helps validate the use of these codes in the blast propagation through tunnels.

A brief look at STUN calculations with and without drag showed that, for a smooth pipe like the one used in the Lunderman and Ohrt experiment, wall drag does not play an important role. The authors are currently extending this research to look at experiments in which the effects of wall roughness are investigated (Lunderman, et al 1993).

This work was performed under the auspices of the US DOE by LLNL under Contract DE-AC5207NA27344 and funded by the Department of Homeland Security, Science and Technology Directorate. 


\section{$\underline{\text { References }}$}

Glenn, L. A. (2001). "Simulating MARVEL with the STUN Code.” LLNL UCRL-ID-143993 (June 6, 2001).

Lunderman, C. and Ohrt, A. P. (1997). "Small-Scale Experiments of In-Tunnel Airblast from Internal and External Detonations." $8^{\text {th }}$ International Symposium on Interactions of the Effects of Munitions with Structures, April 21-25, McLean, Virginia.

Lunderman, C. V., Welch, C. R., Joachim, C. E., and Furey, J. S. (1993). "Effects of Tunnel Wall Roughness on Airblast from Internal Detonations - Results from Small-Scale Experiments." $64^{\text {th }}$ Shock \& Vibration Symposium, October 25-28, Fort Walton Beach, Florida.

Nicols, A. L., and the ALE3D team, (2009). Users Manual for ALE3D, An Arbitrary Lagrange/Eulerian 2D and 3D Code System, Volume 2, Material and Chemical Models, Lawrence Livermore National Laboratory, UCRL-SM-404490 


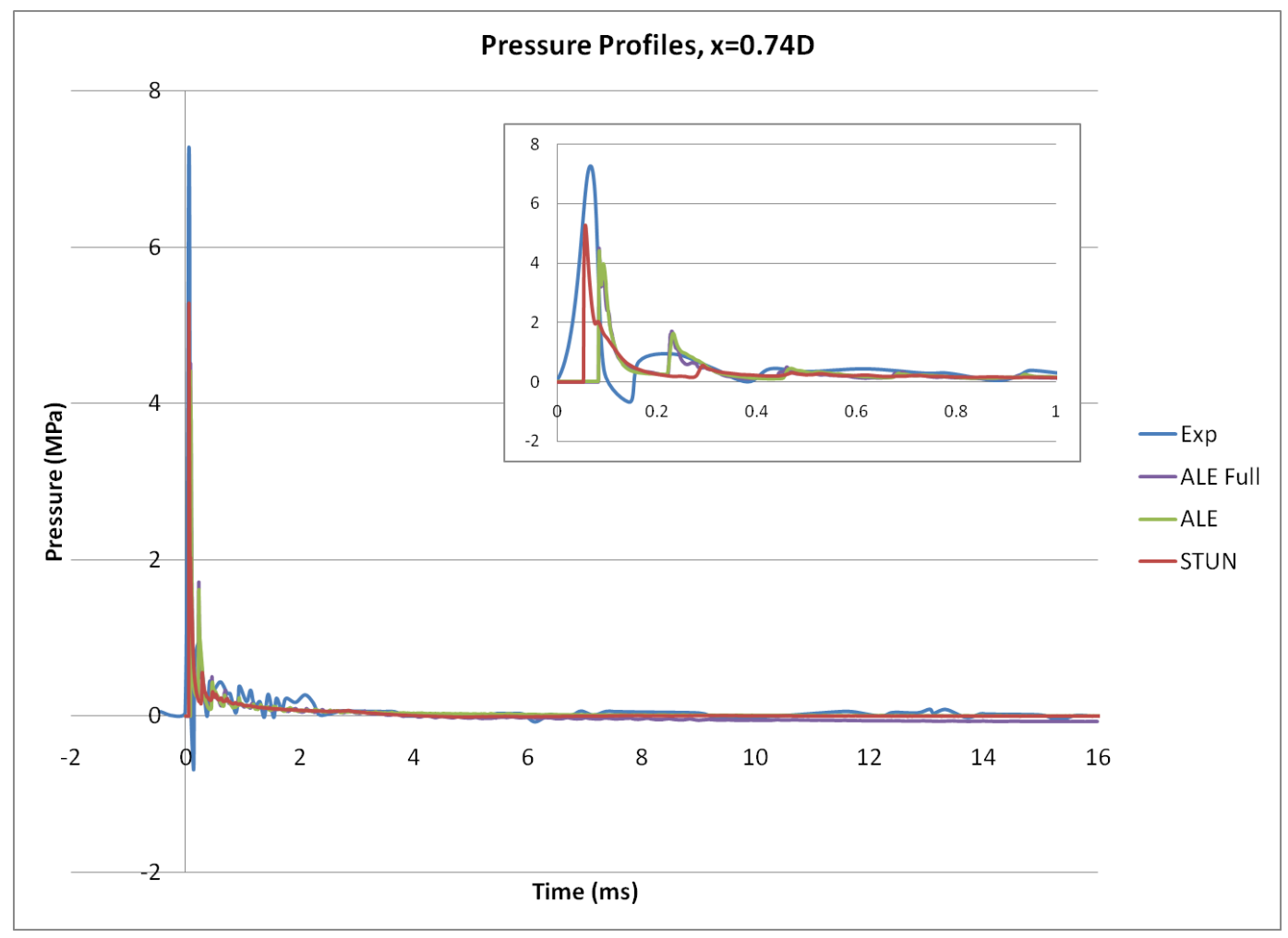

Figure 3: Pressure profiles from three simulations compared to the experiment, $x=0.74 \mathrm{D}$

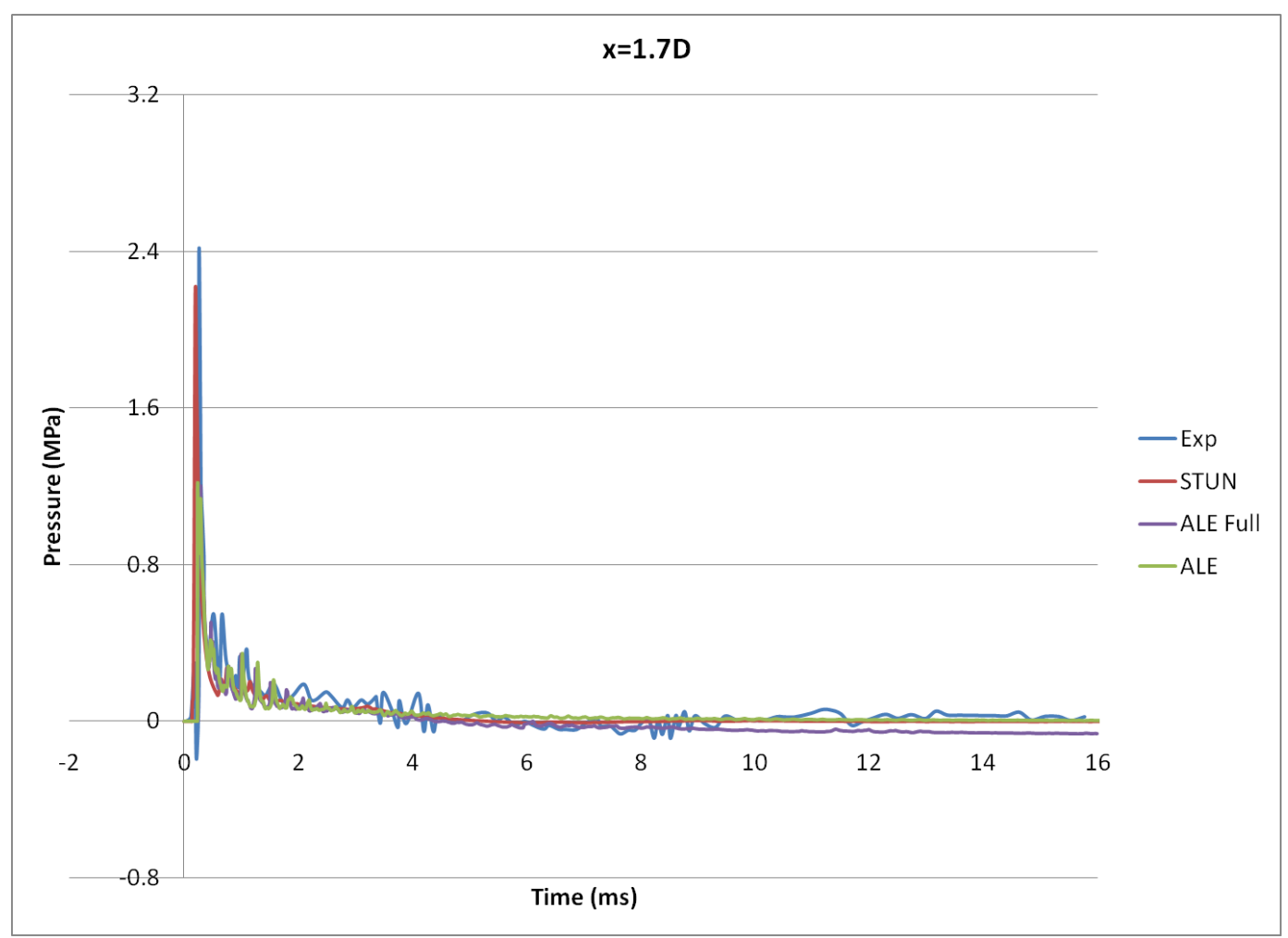

Figure 4: Pressure profiles from three simulations compared to the experiment, $x=1.7 \mathrm{D}$ 


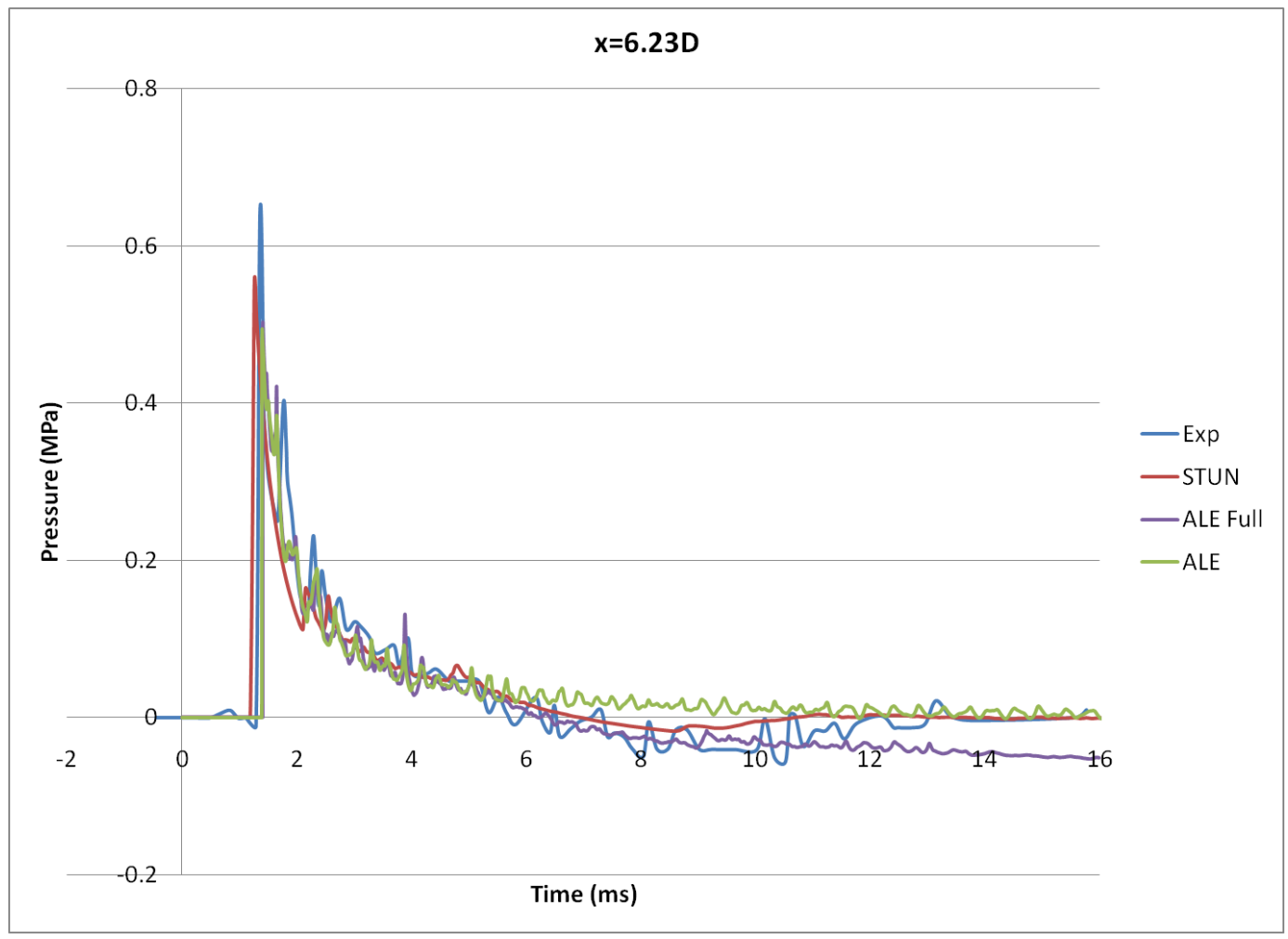

Figure 5: Pressure profiles from three simulations compared to the experiment, $x=6.23 \mathrm{D}$

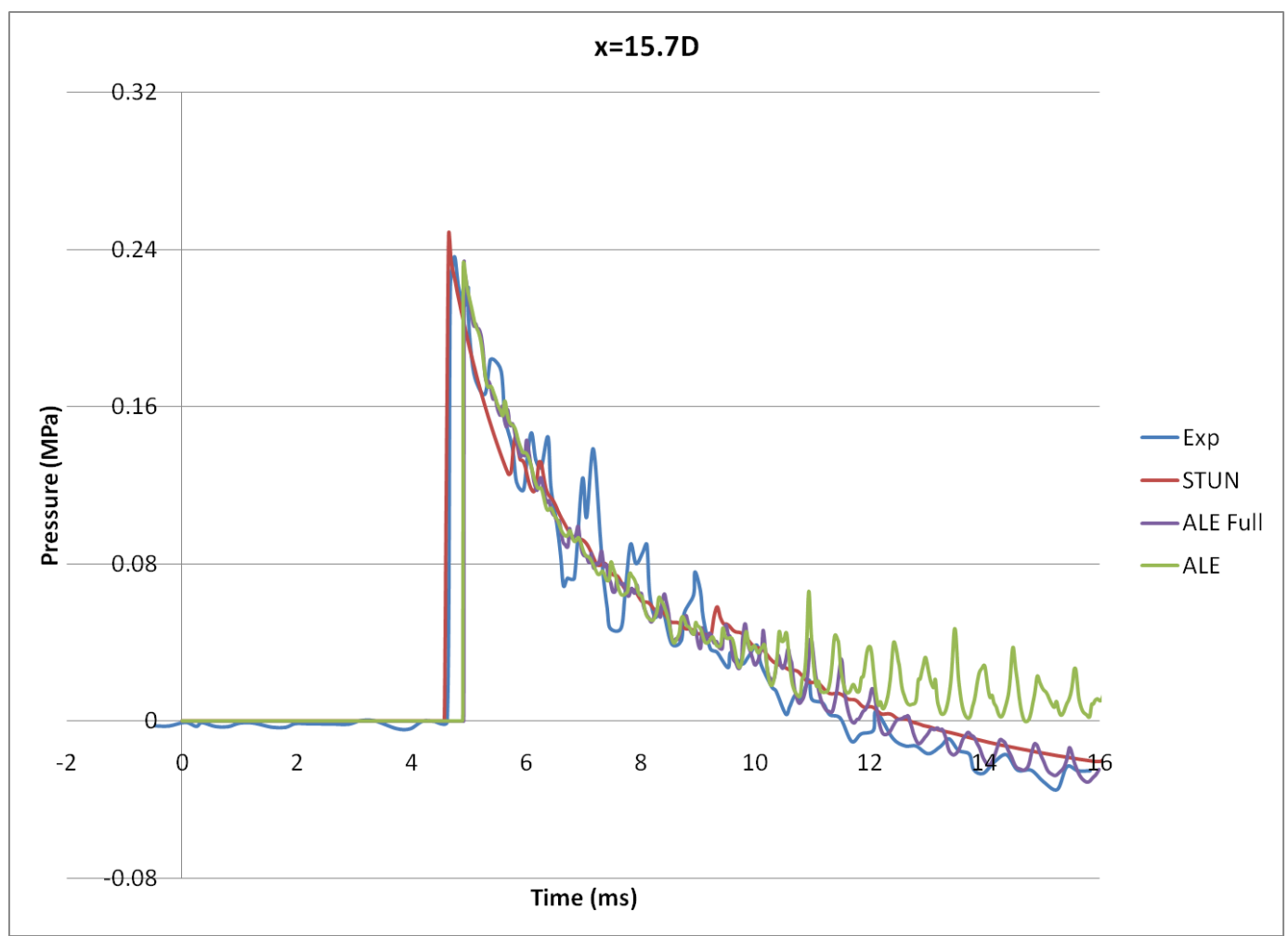

Figure 6: Pressure profiles from three simulations compared to the experiment, $x=15.7 \mathrm{D}$ 


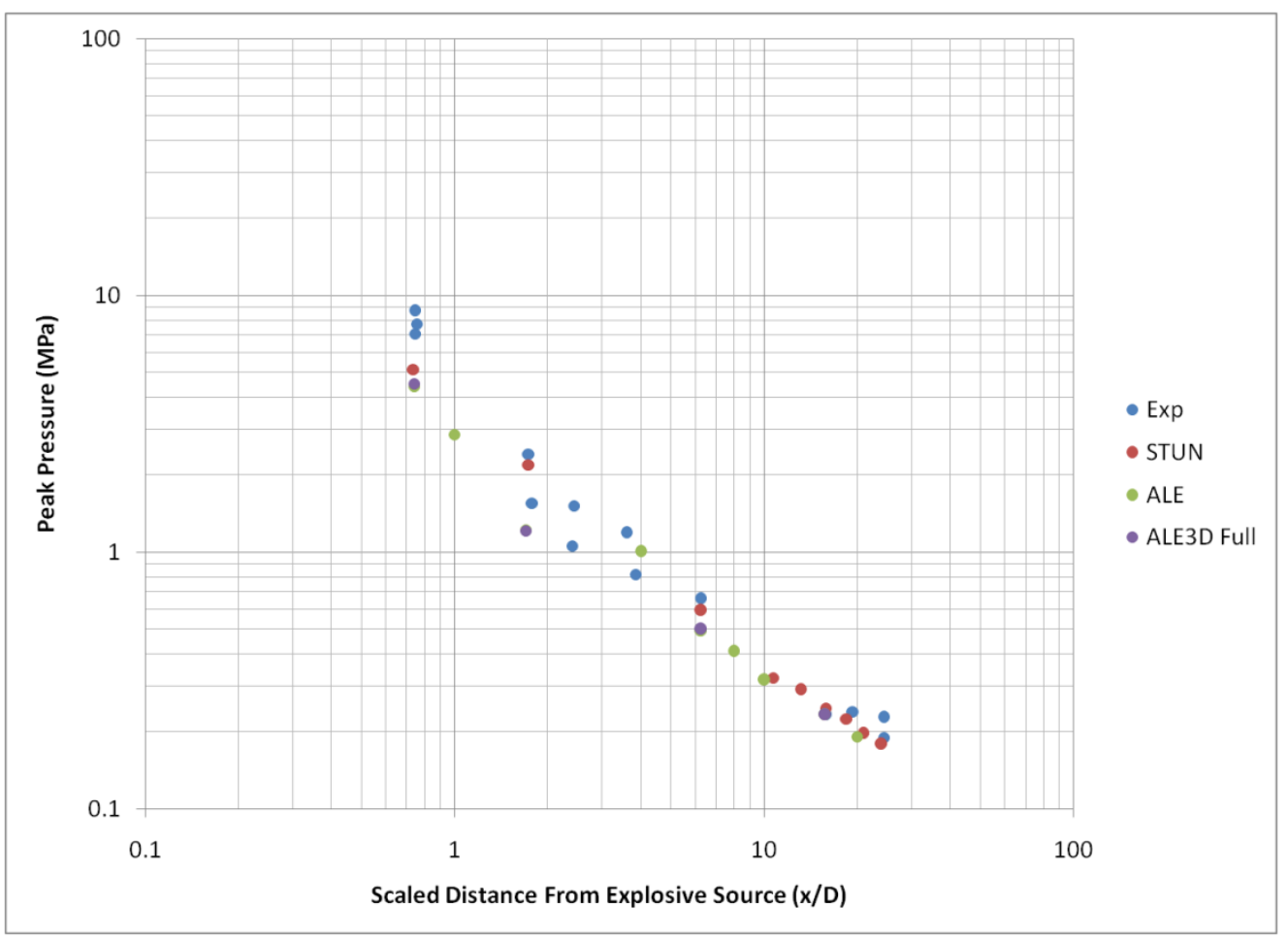

Figure 7: Peak pressure results versus distance from source

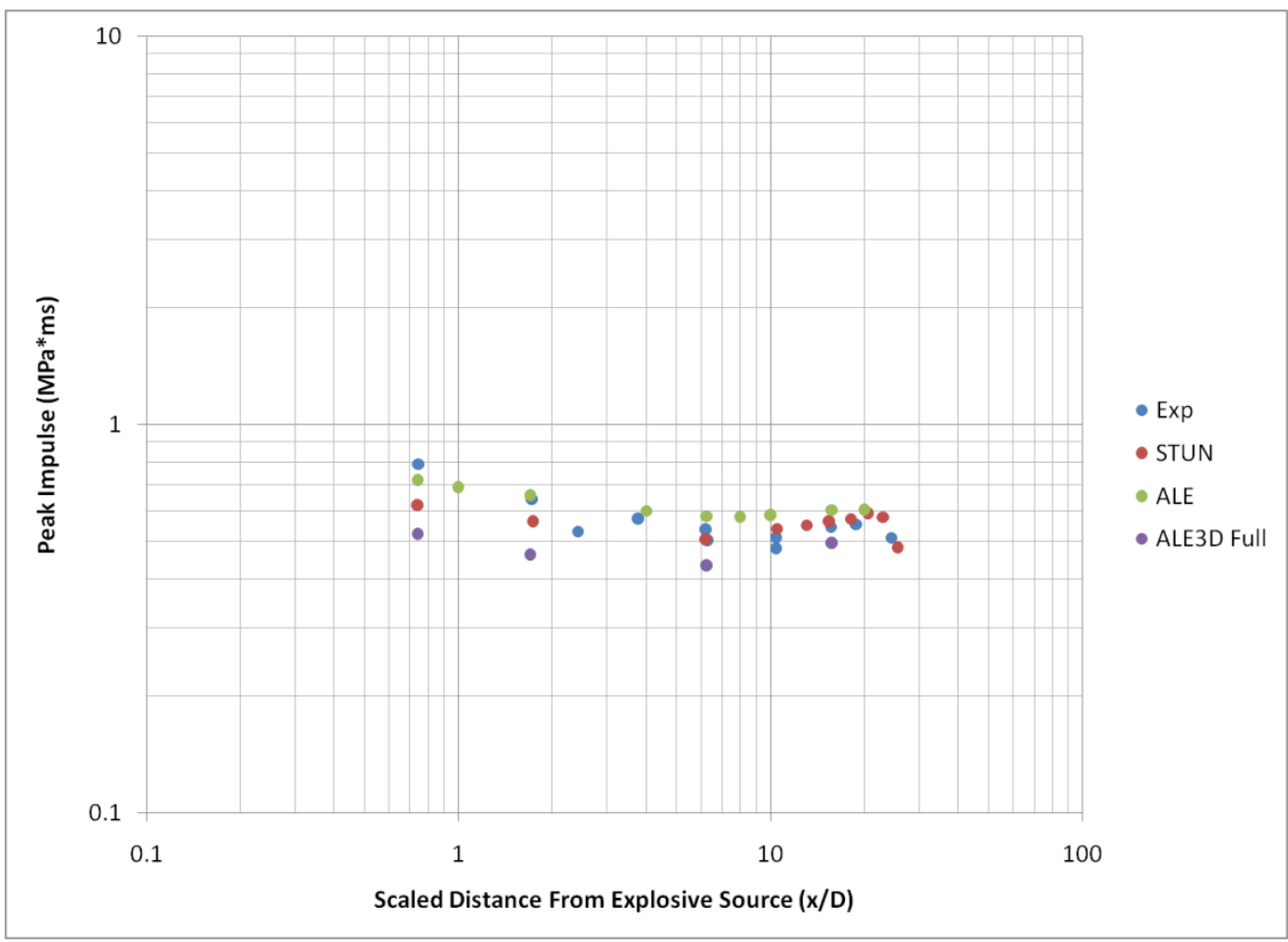

Figure 8: Peak impulse results versus distance from source 